\title{
A eficiência na produção de biomassa e grãos de aveia pelo uso do nitrogênio
}

\author{
Rubia D. Mantai ${ }^{1}$, José A. G. da Silva ${ }^{2}$, Airam T. Z. R. Sausen ${ }^{3}$, \\ Juliane S. P. Costa ${ }^{4}$, Sandra B. V. Fernandes ${ }^{5} \&$ Cassiane Ubessi $^{6}$
}

\section{Palavras-chave:}

Avena sativa L.

ureia

razão $\mathrm{C} / \mathrm{N}$

eficiência técnica e econômica

\begin{abstract}
R E S U M O
A produção de biomassa e grãos de aveia depende diretamente das formas de fornecimento de nitrogênio $(\mathrm{N})$. Propôs-se, com este estudo, determinar a eficiência de aproveitamento de $\mathrm{N}$-fertilizante na elaboração de biomassa e grãos de aveia em distintos sistemas de cultivo e estimar a máxima eficiência técnica e econômica de produtividade de grãos na identificação de cultivares mais eficientes no uso do N. O estudo foi conduzido nos anos de 2011 e 2012, em delineamento experimental de blocos casualizados com quatro repetições em esquema fatorial $4 \times 2$ para Doses de Nitrogênio (0, 30, 60 e $120 \mathrm{~kg} \mathrm{ha}^{-1}$ ) e Cultivares de Aveia (Barbarasul e Brisasul) no sistema soja/aveia e milho/aveia. Há tendência de crescimento na taxa de biomassa em aveia com o incremento das doses de $\mathrm{N}$-fertilizante em ambos os sistemas de cultivo, condição nem sempre acompanhada da maior produtividade de grãos. A cultivar Brisasul mostra maior eficiência no aproveitamento do $\mathrm{N}$ à elaboração de biomassa e grãos, independente do sistema de cultivo. A definição da dose ajustada em aveia permite resultados mais vantajosos pela análise da máxima eficiência econômica de produtividade de grãos.
\end{abstract}

\section{Key words:}

Avena sativa L.

urea

$\mathrm{C} / \mathrm{N}$ ratio

technical efficiency and economic

\section{Efficiency in the production of biomass and oat grains by the use of nitrogen}

\begin{abstract}
A B S T R A C T
The production of biomass and oat grains is directly dependent on the forms of nitrogen (N) supply. The objective of this study was to determine the efficiency of utilization of $\mathrm{N}$-fertilizer on biomass and grain oat in high and reduced $\mathrm{N}$-residual release in different cropping systems and estimate the maximum technical and economic efficiency of grain yield in identifying cultivars more efficient in the use of $\mathrm{N}$. The study was conducted in the years 2011 and 2012 in a randomized block design with four replications in a $4 \times 2$ factorial with four nitrogen rates $\left(0,30,60\right.$ and $\left.120 \mathrm{~kg} \mathrm{ha}^{-1}\right)$ and two oat cultivars (Barbarasul and Brisasul) in soybean/oat and corn/oat system. There is a tendency of increase in growth rate in oat biomass with increasing doses of $\mathrm{N}$-fertilizer in both cropping systems, however, condition is not always accompanied by the increased productivity of grain. The cultivar Brisasul shows greater efficiency in the utilization of $\mathrm{N}$ in the elaboration of biomass and grain, independent of the production system. The definition of adjusted dose in oats allows more advantageous results by analysis of maximum economic efficiency for grain yield.
\end{abstract}

Protocolo 112-2014 - 07/04/2014 • Aprovado em 28/11/2014 • Publicado em 02/03/2015

${ }^{1}$ DCEEng/UNIJUÍ. Ijuí, RS. E-mail: rdmantai@yahoo.com.br

${ }^{2}$ Departamento de Estudos Agrários/UNIJUÍ. Ijuí, RS. E-mail: jagsfaem@yahoo.com.br (Autor correspondente)

${ }^{3}$ DCEEng/UNIJUÍ. Ijuí, RS. E-mail: airamsausen@gmail.com

${ }^{4}$ DCEEng/UNIJUÍ. Ijuí, RS. E-mail: juliane.sbaraine@gmail.com

${ }^{5}$ Departamento de Estudos Agrários/UNIJUÍ. Ijuí, RS. E-mail: sandravf@unijui.edu.br

${ }^{6}$ Departamento de Fitotecnia/UFSM. Santa Maria, RS. E-mail: cassi.ubessi@yahoo.com.br 


\section{INTRODUÇÃo}

A dose e o momento de aplicação do $\mathrm{N}$-fertilizante são fundamentais para incrementar o rendimento de grãos e a produção de biomassa (Takayama et al., 2006; Flores et al., 2012). No entanto, o fornecimento de $\mathrm{N}$ às plantas depende, entre outros fatores, da quantidade de matéria orgânica do solo, da composição dos resíduos vegetais, da expectativa do rendimento e da umidade, aeração e temperatura que interagem entre si nos sistemas de cultivo (Rocha et al., 2008; Siqueira Neto et al., 2010; Costa et al., 2013). As características genéticas das cultivares, condições climáticas e técnicas de cultivo, também atuam sobre a eficiência de uso e aproveitamento do N (Dencic et al., 2011; Prando et al., 2013; Viola et al., 2013).

A aveia-branca (Avena sativa L.) tem assumido grande importância como cultura alternativa na estação fria, em uma ampla área de cultivo no Brasil, sobremaneira nos estados do Sul. Portanto, é cada vez maior a demanda por cultivares altamente produtivas, de elevada qualidade e eficientes em resposta à melhoria de estímulos ambientais (Silva et al., 2012; Hawerroth et al., 2013). Assim, a expressão de potenciais de rendimento da aveia branca, afora os aspectos climáticos, está associada às características genéticas das cultivares e sua interação com as técnicas de manejo, entre elas o controle fitossanitário e a habilidade de uso do N (Benin et al., 2012; Silva et al., 2012). No entanto, expectativa buscando altos rendimentos pode elevar as doses de adubação com $\mathrm{N}$-fertilizante aumentando os custos de produção a ponto de tornar a cultura economicamente inviável (Foulkes et al., 2009; Barraclough et al., 2010), além de danos ambientais, seja por lixiviação do nitrato ou pela volatilização da amônia (Ma et al., 2010).

As mudanças climáticas no planeta têm proporcionado novo desafio na produção agrícola de vez que, afora a obtenção de cultivares mais produtivas e tolerantes a fatores bióticos e abióticos (Araus et al., 2008; Oliveira et al., 2011), existe a necessidade de que sejam mais eficientes no aproveitamento de luz e nutrientes, condição-chave para uma agricultura cada vez mais sustentável (Parry et al., 2011). Desta forma, estudos da eficiência de uso do $\mathrm{N}$ sobre novos genótipos disponíveis são fundamentais para atualizar as recomendações técnicas e disponibilizar tecnologias mais ajustadas trazendo produções economicamente satisfatórias e com menor risco de poluição ambiental (Teixeira Filho et al., 2010; Prando et al., 2013).

Objetivou-se, com este estudo, determinar a eficiência de aproveitamento de $\mathrm{N}$-fertilizante na elaboração de biomassa e grãos de aveia em distintos sistemas de cultivo e estimar a máxima eficiência técnica e econômica de produtividade de grãos na identificação de cultivares mais eficientes no uso do $\mathrm{N}$.

\section{Material e Métodos}

Os trabalhos foram desenvolvidos a campo, nos anos agrícolas de 2011 e 2012, no município de Augusto Pestana, RS. O solo da área experimental foi classificado como Latossolo Vermelho Distroférrico Típico e o clima da região, segundo classificação de Köppen, do tipo Cfa, com verão quente sem estação seca. No estudo foi realizada, dez dias antes da semeadura, análise de solo e identificadas as seguintes características químicas do local: i) sistema milho/aveia ( $\mathrm{pH}$ $=6,5 ; \mathrm{P}=34,4 \mathrm{mg} \mathrm{dm}^{-3} ; \mathrm{K}=262 \mathrm{mg} \mathrm{dm}^{-3} ; \mathrm{MO}=3,5 \% ; \mathrm{Al}=0$ $\mathrm{cmol}_{\mathrm{c}} \mathrm{dm}^{-3} ; \mathrm{Ca}=6,6 \mathrm{cmol}_{\mathrm{c}} \mathrm{dm}^{-3}$ e $\mathrm{Mg}=3,4 \mathrm{cmol}_{\mathrm{c}} \mathrm{dm}^{-3}$ ) e ii) sistema soja/aveia ( $\mathrm{pH}=6,2 ; \mathrm{P}=33,9 \mathrm{mg} \mathrm{dm}^{-3} ; \mathrm{K}=200 \mathrm{mg}$ $\mathrm{dm}^{-3} \mathrm{MO}=3,4 \% ; \mathrm{Al}=0 \mathrm{cmol}_{\mathrm{c}} \mathrm{dm}^{-3} ; \mathrm{Ca}=6,5 \mathrm{cmol}_{c} \mathrm{dm}^{-3} \mathrm{e} \mathrm{Mg}$ $\left.=2,5 \mathrm{cmol}_{\mathrm{c}} \mathrm{dm}^{-3}\right)$. Nesses dois anos a semeadura foi realizada na primeira semana de junho com semeadora-adubadora para composição da parcela constituída de 5 linhas de $5 \mathrm{~m}$ de comprimento e espaçamento entre linhas de $0,20 \mathrm{~m}$, formando a unidade experimental de $5 \mathrm{~m}^{2}$. Durante a execução do estudo foram efetuadas aplicações de fungicida tebuconazole de nome comercial FOLICUR' CE na dosagem de $0,75 \mathrm{~L} \mathrm{ha}^{-1}$. Além disto, o controle de plantas daninhas foi efetuado com herbicida metsulfuron-metil na dose de $4 \mathrm{~g} \mathrm{ha}^{-1}$ do produto comercial e capinas adicionais sempre que necessário. Nos experimentos foram aplicados, na semeadura, 60 e $50 \mathrm{~kg} \mathrm{ha}^{-1}$ de $\mathrm{P}_{2} \mathrm{O}_{5}$ e $\mathrm{K}_{2} \mathrm{O}$, respectivamente, com base nos teores de $\mathrm{P}$ e $\mathrm{K}$ no solo para expectativa de rendimento de grãos de $3 \mathrm{t} \mathrm{ha}^{-1} \mathrm{e}$ de $\mathrm{N}$ na base com $10 \mathrm{~kg} \mathrm{ha}^{-1}$ (exceto na unidade experimental padrão), sendo o restante para contemplar as doses propostas em cobertura no estádio indicado de quarta folha expandida com presença de colar.

$\mathrm{Na}$ condição de cultivo com cobertura residual de elevada e reduzida relação $\mathrm{C} / \mathrm{N}$ (sistema milho/aveia e soja/aveia) respectivamente, dois experimentos foram conduzidos, um para quantificar a taxa de produção de biomassa pelos cortes realizados a cada 30 dias até o ponto de colheita e o outro para a colheita no final do ciclo, visando exclusivamente à estimativa da produtividade de grãos. Portanto, nos quatro experimentos o delineamento experimental foi o de blocos casualizados com quatro repetições, seguindo um esquema fatorial 4 x 2 nas fontes de variação Doses de $\mathrm{N}$-fertilizante (fonte ureia) e Cultivares de aveia, respectivamente. Enquanto as fontes de variação com seus respectivos níveis em cada sistema de cultivo foram: i) Doses de nitrogênio (0, 30, 60 e $\left.120 \mathrm{~kg} \mathrm{ha}^{-1}\right)$ e Cultivares de aveia (Barbarasul e Brisasul) totalizando 64 unidades experimentais. A colheita dos experimentos para a estimativa do rendimento de grãos em cada sistema de cultivo ocorreu de forma manual pelo corte das três linhas centrais de cada parcela. O momento de colheita de grãos foi aquele também definido como o último corte no experimento direcionado à análise da produção de biomassa (120 dias), estádio próximo ao ponto de colheita, com umidade de grãos ao redor de 15\%; em seguida, as parcelas foram trilhadas com colheitadeira estacionária e direcionadas ao laboratório para correção da umidade de grãos para $13 \%$ e pesagem para estimativa da produtividade convertida para a unidade de um hectare. Nos experimentos visando quantificar a biomassa total ao longo do desenvolvimento das plantas, a colheita do material vegetal foi realizada rente ao solo, a partir da coleta de um metro linear das três linhas centrais de cada parcela, no período de 30, 60, 90 e 120 dias após a emergência, totalizando quatro cortes. As amostras com a biomassa verde foram pesadas em balança de precisão e direcionadas à estufa de ar forçado na temperatura de $65^{\circ} \mathrm{C}$, até atingir peso constante, com posterior estimativa da matéria seca total convertida em $\mathrm{kg} \mathrm{ha}^{-1}$.

Ao atender aos pressupostos de homogeneidade e normalidade via testes de Bartlet e Liliefors, foi realizada análise de variância para detecção dos efeitos principais e 
de interação. Com base nessas informações procedeu-se ao ajuste de equação linear (MST $\left.=\mathrm{b}_{0} \pm \mathrm{b}_{1} \mathrm{x}\right)$ na estimativa da taxa de biomassa $\mathrm{d}^{-1} \mathrm{ha}^{-1}$ e de médias por Scott \& Knott em cada dose do nitrogênio e em seguida, com o ajuste de equação de grau dois $\left(\mathrm{RG}=\mathrm{b}_{0} \pm \mathrm{b}_{1} \mathrm{x} \pm \mathrm{b}_{2} \mathrm{x}^{2}\right)$ para a estimativa da máxima eficiência técnica $\left(\mathrm{MET}=-\left[\left(\mathrm{b}_{1}\right) /\left(2 \mathrm{~b}_{2}\right)\right]\right)$ e econômica $(\mathrm{MEE}=$ $\left.\left[(\mathrm{t} / \mathrm{w})-\mathrm{b}_{1}\right] /\left(2 \mathrm{~b}_{2}\right)\right)$ de produtividade de grãos. Para a máxima eficiência econômica estão incluídos, no modelo, o preço do produto $(\mathrm{w})$ e o preço do insumo $(\mathrm{t})$. Os valores utilizados representam os preços médios praticados na região noroeste do Rio Grande do Sul sendo o preço do insumo (nitrogênio) de $R \$ 1,18 \mathrm{~kg}^{-1}$ e do produto aveia de $\mathrm{R} \$ 0,41 \mathrm{~kg}^{-1}$. Visando às determinações, foi empregado o programa computacional Genes (Cruz, 2013).

\section{Resultados e Discussão}

No estudo, as fontes de variação doses de N (DN), cultivares (C) e anos de cultivo (A) mostraram interação complexa (DN $\mathrm{x} \mathrm{C}$ x A) sobre a biomassa total (MST) e o rendimento de grãos (RG) (não apresentado), condição que justifica a forma de apresentação das tabelas buscando o desdobramento. No sistema soja/aveia, em 2011 (Tabela 1), as equações obtidas indicaram tendência linear na cultivar Barbarasul. A maior taxa de biomassa foi obtida na dose mais elevada de $\mathrm{N}$ indicando que nesta condição houve acréscimo de $119 \mathrm{~kg} \mathrm{ha}^{-1}$ de biomassa produzida por dia. Ligando a taxa de biomassa produzida ao dia com os valores médios de produtividade de grãos em cada ponto de adubação, a dose de 30 e $60 \mathrm{~kg} \mathrm{ha}^{-1}$ de $\mathrm{N}$ mostrou-se mais ajustada na cultivar Barbarasul cujos resultados revelam que a dose mais elevada mobiliza, em grande parte, o aproveitamento do $\mathrm{N}$ à produção de palha, não refletindo na maior conversão em grãos. Portanto, doses elevadas de $\mathrm{N}$, além de não mostrar efetividade sobre a massa de grãos pode favorecer o crescimento vegetativo exagerado acarretando em perdas significativas em produtividade $\mathrm{e}$ qualidade de grãos pelo acamamento (Barraclough et al., 2010; Silva et al., 2012). Na cultivar Brisasul (Tabela 1) ligando a equação linear do acúmulo de biomassa e o valor médio de produtividade de grãos, apenas a dose de $60 \mathrm{~kg} \mathrm{~N} \mathrm{ha}^{-1}$ se mostrou de melhor aproveitamento; inclusive, com esta cultivar evidenciando maior eficiência no aproveitamento do $\mathrm{N}$ na produção de palha e de grãos em relação à Barbarasul (Tabela 1). Portanto, mesmo indicando forte similaridade morfológica e proveniente de mesmos genitores (Carvalho et al., 2009; Oliveira et al., 2011), mostram diferenças genéticas decisivas que qualificam a importância dessas informações no melhor ajuste de recomendação. Em 2012 (Tabela 1), redução na taxa de biomassa ao dia foi observada na comparação com o ano anterior identificando, porém, condições mais restritas ao cultivo da aveia, sobretudo por elementos climáticos durante o ciclo de cultivo (Figura 1). A variabilidade do solo e o clima alteram a disponibilidade de $\mathrm{N}$ e sua exigência pela planta restringindo a produtividade vegetal (Simili et al., 2008; Espindula et al., 2010). Benin et al. (2012) observaram, em trigo, maior resposta à produtividade de grãos pelo $\mathrm{N}$ quando as chuvas não eram limitantes.

A resposta observada nas cultivares Barbarasul e Brisasul no ano mais favorável de cultivo (2011) evidencia que o emprego de dose elevada com $\mathrm{N}$, mesmo com maior taxa de biomassa diária, não é eficiente no incremento da produtividade de grãos (Tabela 1). Tem-se observado, em condições altamente favoráveis de cultivo, que o uso de elevados níveis de $\mathrm{N}$ nem sempre é o mais indicado permitindo, com melhorias no sistema, já atingir o máximo aproveitamento pela planta com menor adubação (Benin et al., 2012). Tal fato favorece menores

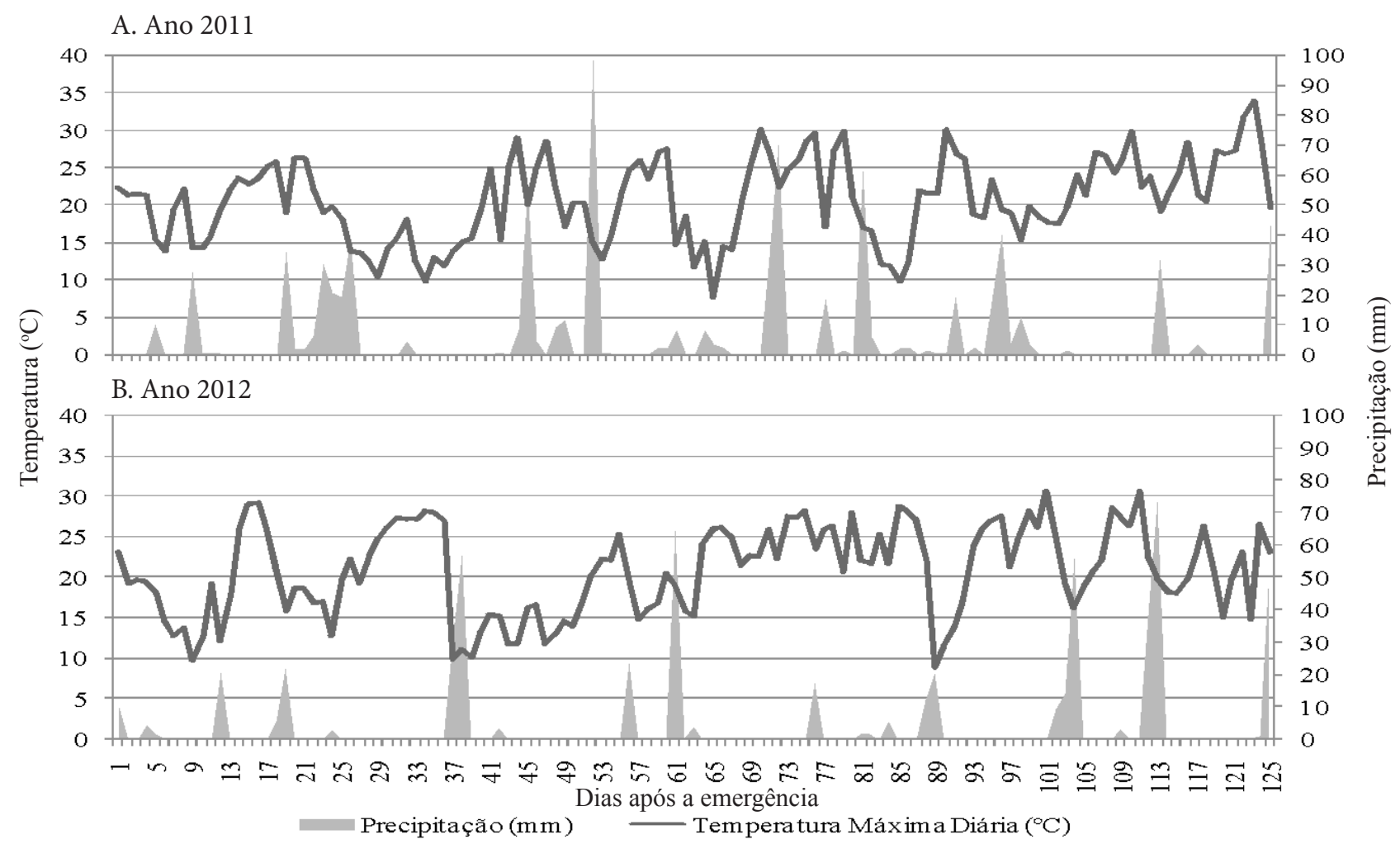

Figura 1. Precipitação pluviométrica e temperatura máxima no ciclo da aveia 
Tabela 1. Equação linear da massa seca total (MST, $\mathrm{kg} \mathrm{ha}^{-1}$ ) em dias após a emergência e valores médios de rendimento de grãos (RG) em cultivares de aveia nas doses de $\mathrm{N}$ no sistema soja/aveia

\begin{tabular}{|c|c|c|c|c|c|}
\hline Cultivar & $\begin{array}{c}\text { Dose N } \\
\left(\mathrm{kg} \mathrm{ha}^{-1}\right)\end{array}$ & $\begin{array}{c}\text { Equação } \\
M S T=b_{0} \pm b_{1} x\end{array}$ & $\mathbf{R}^{2}$ & $\begin{array}{c}P \\
\left(b_{i x}\right)\end{array}$ & $\begin{array}{c}\mathrm{RG} \\
\left(\mathrm{kg} \mathrm{ha}^{-1}\right)\end{array}$ \\
\hline & & Ano 2011 & & & \\
\hline \multirow{4}{*}{ Barbarasul } & 0 & $3252+94,4 x$ & 0,90 & * & $2957 b$ \\
\hline & 30 & $3369+103,7 x$ & 0,95 & * & $3715 \mathrm{a}$ \\
\hline & 60 & $3583+106,3 x$ & 0,95 & * & $3769 a$ \\
\hline & 120 & $4192+119,4 x$ & 0,94 & * & $3233 b$ \\
\hline \multirow{4}{*}{ Brisasul } & 0 & $2496+70,1 x$ & 0,81 & * & $3299 \mathrm{c}$ \\
\hline & 30 & $4057+109,3 x$ & 0,90 & * & $3671 b$ \\
\hline & 60 & $4503+121,8 x$ & 0,89 & * & $4477 \mathrm{a}$ \\
\hline & 120 & $4150+117,4 x$ & 0,93 & * & $2942 d$ \\
\hline & & Ano 2012 & & & \\
\hline \multirow{4}{*}{ Barbarasul } & 0 & $2002+76,7 x$ & 0,89 & * & $2652 b$ \\
\hline & 30 & $2644+87,9 x$ & 0,84 & * & $2978 \mathrm{a}$ \\
\hline & 60 & $2282+83,9 x$ & 0,89 & * & $3052 \mathrm{a}$ \\
\hline & 120 & $3633+116,9 x$ & 0,91 & * & 3009 a \\
\hline \multirow{4}{*}{ Brisasul } & 0 & $1764+73,6 x$ & 0.88 & * & $2582 b$ \\
\hline & 30 & $4009+110,5 x$ & 0,95 & * & $3142 \mathrm{a}$ \\
\hline & 60 & $3115+107,0 x$ & 0,87 & * & $3049 a$ \\
\hline & 120 & $2749+103,6 x$ & 0,90 & * & $2898 a$ \\
\hline
\end{tabular}

$\mathrm{R}^{2}$ - Coeficiente de determinação; $P\left(b_{\text {. }}\right)$ - Parâmetro de inclinação da reta; *Significância do parâmetro de inclinação da reta a 0,05 de probabilidade de erro pelo teste t; Médias seguidas pelas mesmas letras constituem grupo estatisticamente homogêneo por cultivar pelo teste Skott \& Knott a 0,05 de probabilidade de erro

perdas com o $\mathrm{N}$ na lavoura, condição que também pode ser alcançada em anos mais restritivos à produção (Barraclough et al., 2010). Portanto, elevados níveis de $\mathrm{N}$ podem prejudicar as culturas além de tornar a planta mais vulnerável ao acamamento, sem contar os danos ao ambiente através de lixiviação ou volatilização de nitratos, com perdas econômicas aos agricultores (Ma et al., 2010; Costa et al., 2013).

Na Tabela 2, no sistema milho/aveia, condição de menor disponibilidade de N-residual pela palhada, independente

Tabela 2. Equação linear da massa seca total (MST, $\left.\mathrm{kg} \mathrm{ha}^{-1}\right)$ em dias após a emergência e valores médios de rendimento de grãos (RG, $\left.\mathrm{kg} \mathrm{ha}^{-1}\right)$ em cultivares de aveia nas doses de $\mathrm{N}$ no sistema milho/aveia

\begin{tabular}{|c|c|c|c|c|c|}
\hline Cultivar & $\begin{array}{c}\text { Dose N } \\
\left(\mathrm{kg} \mathrm{ha}^{-1}\right)\end{array}$ & $\begin{array}{c}\text { Equação } \\
\text { MST }=b_{0} \pm b_{1} x\end{array}$ & $\mathbf{R}^{2}$ & $\begin{array}{c}P \\
\left(b_{1 x}\right)\end{array}$ & $\begin{array}{c}\mathrm{RG} \\
\left(\mathrm{kg} \mathrm{ha}^{-1}\right)\end{array}$ \\
\hline & & Ano 2011 & & & \\
\hline \multirow{4}{*}{ Barbarasul } & 0 & $2003+53,8 x$ & 0,80 & * & $1963 \mathrm{C}$ \\
\hline & 30 & $2373+67,6 x$ & 0,86 & * & $2522 \mathrm{~b}$ \\
\hline & 60 & $3081+90,4 x$ & 0,92 & * & $3012 \mathrm{a}$ \\
\hline & 120 & $2944+109,7 x$ & 0,98 & * & 3031 a \\
\hline \multirow{4}{*}{ Brisasul } & 0 & $1516+47,2 x$ & 0,87 & * & $2073 \mathrm{c}$ \\
\hline & 30 & $2049+65,2 x$ & 0,92 & * & $2645 b$ \\
\hline & 60 & $2066+76,9 x$ & 0,97 & * & $2994 \mathrm{a}$ \\
\hline & 120 & $3782+119,1 x$ & 0,97 & * & $2612 b$ \\
\hline \multirow{5}{*}{ Barbarasul } & & Ano 2012 & & & \\
\hline & 0 & $1418+45,3 x$ & 0,96 & * & $1150 \mathrm{C}$ \\
\hline & 30 & $2463+81,5 x$ & 0,90 & * & $2235 b$ \\
\hline & 60 & $2691+90,0 x$ & 0,83 & * & $2706 \mathrm{a}$ \\
\hline & 120 & $3378+101,3 x$ & 0,93 & * & $2833 a$ \\
\hline \multirow{4}{*}{ Brisasul } & 0 & $1079+41,8 x$ & 0,86 & * & $1475 d$ \\
\hline & 30 & $2389+78,2 x$ & 0,80 & * & $2750 \mathrm{c}$ \\
\hline & 60 & $2506+80,7 x$ & 0,84 & * & $2948 b$ \\
\hline & 120 & $3357+95,0 x$ & 0,94 & * & $3206 \mathrm{a}$ \\
\hline
\end{tabular}

$\mathrm{R}^{2}$ - Coeficiente de determinação; $\mathrm{P}(\mathrm{b}$. $)$ - Parâmetro de inclinação da reta; * Significância do parâmetro de inclinação da reta a 0,05 de probabilidade de erro pelo teste t; Médias seguidas pelas mesmas letras constituem grupo estatisticamente homogêneo por cultivar pelo teste Skott \& Knott a 0,05 de probabilidade de erro do ano e da cultivar, o acréscimo das doses de $\mathrm{N}$ também proporcionou tendência de crescimento linear na taxa de produção de biomassa ao dia; em 2011 tanto a cultivar Barbarasul como a Brisasul indicaram simultaneamente melhor ajuste na produção de biomassa e de grãos com 60 $\mathrm{kg} \mathrm{ha}^{-1}$ de N. Ressalta-se, nesta condição, a maior eficiência na taxa de biomassa conferida pela cultivar Barbarasul. $\mathrm{Na}$ cultivar Barbarasul foi constatado, no ano de 2012 (Tabela 2) que o ponto de observação com $\mathrm{N}$ de $60 \mathrm{~kg} \mathrm{ha}^{-1}$ se mostrou ajustado na produção de biomassa e grãos. Por outro lado, na Brisasul a maior produção de biomassa e grãos foi alcançada com a dose mais elevada do nutriente.

Nesta condição mais restrita de cultivo, tanto pelo N-residual (sistema milho/aveia) e condições climáticas, a Brisasul segue mostrando maior eficiência de aproveitamento de $\mathrm{N}$ na conversão de palha e de grãos. Ressalta-se que a dose $30 \mathrm{~kg} \mathrm{ha}^{-1}$ de $\mathrm{N}$ resultou em acréscimo de $83 \%$ de biomassa total em relação à dose padrão neste sistema. Ressalta-se que as diferenças de uso nas doses de $\mathrm{N}$ dependem da cultura antecessora, da produtividade esperada, do histórico da área e do sistema de manejo (Silva et al., 2012). A produtividade de biomassa e de grãos de aveia se mostra favorecida pelo sistema soja/aveia, reforçando os efeitos decisivos da relação $\mathrm{C} / \mathrm{N}$ da palhada sobre o solo na produtividade vegetal, afora a redução da dependência de fertilizantes nitrogenados (Silva et al., 2006). Heinemann et al. (2006) observaram que a deficiência de $\mathrm{N}$ reduz a captação da radiação solar pelo trigo com reflexos diretos sobre a produção de biomassa e de grãos. O déficit hídrico no solo também é decisivo em dificultar os processos envolvidos na nutrição vegetal, mostrando que a produtividade de grãos pela maior eficiência de uso do $\mathrm{N}$ pode ser consideravelmente aumentada com adequada umidade no solo (Cazetta et al., 2008).

Na Tabela 3, buscando a máxima eficiência técnica (MET) de produtividade de grãos pelo uso do nitrogênio foram obtidas em 2011, no sistema soja/aveia, doses ajustadas em 66 e $76 \mathrm{~kg} \mathrm{ha}^{-1}$ de N nas cultivares Barbarasul e Brisasul com estimativa de produtividade de grãos ao redor de 3874 e 4360 $\mathrm{kg} \mathrm{ha}^{-1}$, respectivamente; no mesmo ano (Tabela 3) de condição mais restritiva pelo clima (Figura 1), as equações indicaram máxima produtividade de grãos na Barbarasul com $92 \mathrm{~kg}$ $\mathrm{ha}^{-1}$ de N em alcançar $3172 \mathrm{~kg} \mathrm{ha}^{-1}$ de grãos; portanto, afora evidenciar forte redução de produtividade em mais de $700 \mathrm{~kg}$ $\mathrm{ha}^{-1}$, mostra expressivo incremento de $\mathrm{N}$-fertilizante em mais de $25 \mathrm{~kg} \mathrm{ha}^{-1}$. Por outro lado, a Brisasul manteve valor similar de produtividade de grãos frente à Barbarasul, porém com apenas $65 \mathrm{~kg} \mathrm{ha}^{-1}$ de $\mathrm{N}$ à máxima eficiência técnica.

A Brisasul mostrou redução de $\mathrm{N}$-fertilizante em quase 30 $\mathrm{kg} \mathrm{ha}^{-1}$ do nutriente em relação à Barbarasul, principalmente em relação ao ano anterior (Tabela 3). Tal fato reforça a necessidade de estudos desta natureza, em virtude de grande número de cultivares em lançamento permitindo prever seu gasto energético e a eficiência de transformação, ponto decisivo na indicação de cultivares mais ajustados na busca de uma agricultura mais sustentável. Penckowski et al. (2009) mostraram, em trigo, que o uso de $\mathrm{N}$, variando de 90 até $225 \mathrm{~kg} \mathrm{ha}^{-1}$ não apresentou respostas significativas de produtividade de grãos em condições favoráveis. Em trigo irrigado Heinemann et al. (2006) observaram resposta positiva 
Tabela 3. Resumo da análise de variância de regressão e parâmetros da equação na estimativa da máxima eficiência técnica (MET) de rendimento de grãos (RG) pelas doses de $\mathrm{N}$ em aveia

\begin{tabular}{|c|c|c|c|c|c|c|c|}
\hline \multirow{2}{*}{ Cultivar } & \multirow{2}{*}{ Fonte de variação } & \multirow{2}{*}{$\begin{array}{l}\text { QM } \\
\text { (RG) }\end{array}$} & \multirow{2}{*}{$\begin{array}{c}\text { Equação } \\
R G=b_{0} \pm b_{1} x \pm b_{2} x^{2}\end{array}$} & \multirow{2}{*}{$P\left(b_{i x}\right)$} & \multirow{2}{*}{$\mathbf{R}^{2}$} & N/MET & $\mathrm{RG}_{\mathrm{E}}$ \\
\hline & & & & & & \multicolumn{2}{|c|}{$\left(\mathrm{kg} \mathrm{ha}^{-1}\right)$} \\
\hline & & & tema Soja/Aveia Ano 2011 & & & & \\
\hline \multirow{3}{*}{ Barbarasul } & L & $29829^{\text {ns }}$ & - & - & - & & \\
\hline & Q & $1724526 *$ & $2997+26,5 x-0,20 x^{2}$ & * & 0,87 & 66 & 3874 \\
\hline & Erro & 39278 & - & - & - & & \\
\hline \multirow{3}{*}{ Brisasul } & L & $283791^{*}$ & $3575+4,70 x$ & * & 0,24 & & \\
\hline & $Q$ & $4188497^{\star}$ & $3202+30,4 x-0,20 x^{2}$ & * & 0,81 & 76 & 4360 \\
\hline & Erro & 15774 & & - & - & & \\
\hline \multicolumn{8}{|c|}{ Sistema Soja/Aveia Ano 2012} \\
\hline \multirow{3}{*}{ Barbarasul } & $\mathrm{L}$ & $198294^{\star}$ & $2791+2,50 x$ & ns & - & & \\
\hline & $Q$ & $192314^{\star}$ & $2668+11 x-0,06 x^{2}$ & * & 0,97 & 92 & 3172 \\
\hline & Erro & 18423 & - & - & - & & \\
\hline \multirow{3}{*}{ Brisasul } & $\mathrm{L}$ & $76083^{\text {ns }}$ & - & - & 0,10 & & \\
\hline & Q & $501498^{*}$ & $2636+15,34 x-0,11 x^{2}$ & * & 0,79 & 69 & 3170 \\
\hline & Erro & 21172 & - & - & - & & \\
\hline \multicolumn{8}{|c|}{ Sistema Milho/Aveia Ano 2011} \\
\hline \multirow{3}{*}{ Barbarasul } & $\mathrm{L}$ & $2308641^{*}$ & $2183+8,56 x$ & * & 0,75 & & \\
\hline & Q & $727371^{\star}$ & $1942+25,16 x-0,13 x^{2}$ & $\star$ & 0,99 & 96 & 3159 \\
\hline & Erro & 23162 & - & - & - & & \\
\hline \multirow{3}{*}{ Brisasul } & $\mathrm{L}$ & $470105^{\star}$ & $2378+3,86 x$ & * & 0,27 & & \\
\hline & $Q$ & $1259034^{*}$ & $2061+25,71 x-0,17 x^{2}$ & * & 0,99 & 75 & 3033 \\
\hline & Erro & 14999 & - & - & - & & \\
\hline \multicolumn{8}{|c|}{ Sistema Milho/Aveia Ano 2012} \\
\hline \multirow{3}{*}{ Barbarasul } & L & $5166571^{*}$ & $1558+12,8 x$ & * & 0,73 & & \\
\hline & $Q$ & $1818021^{*}$ & $1178+39,06 x-0,21 x^{2}$ & * & 0,99 & 93 & 2994 \\
\hline & Erro & 12569 & - & - & - & & \\
\hline \multirow{3}{*}{ Brisasul } & $\mathrm{L}$ & $4997068^{*}$ & $1934+12,59 x$ & * & 0,70 & & \\
\hline & Q & $1758918^{\star}$ & $1560+38,42 x-0,20 x^{2}$ & * & 0,95 & 96 & 3405 \\
\hline & Erro & 13709 & - & - & - & & \\
\hline
\end{tabular}

QM - Quadrado médio; $L$ - Equação linear; $Q$ - Equação quadrática; $R^{2}$ - Coeficiente de determinação; $P\left(b_{i x}\right)$ - Parâmetro de inclinação da reta * Significância do parâmetro de inclinação a 0,05 de probabilidade de erro pelo teste t; ns - Não significativo a 0,05 de probabilidade de erro; $R_{\mathrm{E}}$ - Rendimento de grãos estimado pela MET

em até $156 \mathrm{~kg} \mathrm{ha}^{-1}$ de $\mathrm{N}$, com produtividade de grãos de 6472 $\mathrm{kg} \mathrm{ha}^{-1}$. No sistema milho/aveia, no ano de 2011 (Tabela 3), as equações apresentadas reforçam a habilidade de menor uso de N pela cultivar Brisasul em expressar a máxima produtividade de grãos. Na condição de menor relação $\mathrm{C} / \mathrm{N}$ (Tabela 3) e considerando o ano mais restritivo (2012) observou-se que as duas cultivares expressaram MET no uso de $\mathrm{N}$ ao redor de $95 \mathrm{~kg} \mathrm{~N} \mathrm{ha}^{-1}$ porém com a cultivar Brisasul maximizando sua capacidade de expressão na elaboração de grãos. Kolchinski \& Schuch (2003) encontraram resultados semelhantes em aveia sinalizando máximas produtividades de grãos em até $73 \mathrm{~kg}$ ha $^{-1}$ de N; já em trigo os melhores resultados com fertilização foram obtidos em níveis de $\mathrm{N}$, que vão de 70 a $120 \mathrm{~kg} \mathrm{ha}^{-1}$ sem irrigação (Espindula et al., 2010; Teixeira Filho et al., 2010). Percebe-se, na Tabela 3, que o sistema de cultivo se mostrou decisivo na modificação da máxima eficiência técnica em particular na cultivar de menor habilidade de uso do $\mathrm{N}$, ou seja, uma condição que levanta a hipótese de uma tendência similar entre as demais cultivares de aveia que evidenciam reduzida eficiência de uso com N. Ressalta-se serem expressivos os resultados obtidos no sistema soja/aveia pela rápida mineralização de resíduos e liberação de N-residual. Por outro lado e mesmo o sistema milho/aveia pareça indesejável tem permitido, em lavouras comerciais, resultados benéficos de controle de plantas daninhas pelo acúmulo e permanência de biomassa sobre o solo, afora a expressiva redução de acamamento em aveia pela taxa de crescimento mais reduzida da cultura trazendo reflexos benéficos sobre a qualidade de grãos à indústria (Silva et al., 2012).
Preconizando um ajuste da dose de $\mathrm{N}$ à planta aliada à redução de contaminação e custos de produção, estão apresentados, na Tabela 4, os valores da máxima eficiência econômica (MEE) de produtividade de grãos. Em 2011 as cultivares Barbarasul e Brisasul expressaram, no sistema soja/ aveia, a MEE, com 58 e $68 \mathrm{~kg} \mathrm{~N} \mathrm{ha}^{-1}$, respectivamente. Nessas condições e mesmo a Brisasul necessitando apenas de $10 \mathrm{~kg} \mathrm{ha}^{-1}$ a mais de N para a MEE, a superioridade de produção de grãos se manteve ao redor de $500 \mathrm{~kg} \mathrm{ha}^{-1}$ a mais que a Barbarasul. No ano de 2012 (condição mais restritiva), embora as cultivares apresentassem produção de grãos similar, a Brisasul exigiu 10 $\mathrm{kg} \mathrm{ha}^{-1}$ a menos de $\mathrm{N}$, reforçando seu potencial como genótipo ecologicamente mais ajustado. A diferença de uso do $\mathrm{N}$ pela eficiência técnica e econômica tornou-se muita expressiva, como exemplo, a Barbarasul, com MET de $92 \mathrm{~kg} \mathrm{ha}^{-1}$ de N para uma produtividade de grãos em $3172 \mathrm{~kg} \mathrm{ha}^{-1}$ de grãos e sua MEE em $65 \mathrm{~kg} \mathrm{~N} \mathrm{ha}^{-1}$ com inexpressiva redução para $3159 \mathrm{~kg}$ $\mathrm{ha}^{-1}$. Uma redução em mais de $30 \%$ na dose de $\mathrm{N}$-fertilizante com o rendimento de grãos praticamente inalterado.

No sistema milho/aveia, no ano de 2011 (Tabela 4), a MEE da cultivar Brisasul ainda se mostrou mais expressiva denotando uma redução do uso do $\mathrm{N}$ em quase $20 \mathrm{~kg} \mathrm{~N}^{-1}$ em relação à Barbarasul cujo fato reforça a possibilidade de ganhos efetivos na redução de custos de produção, bem como do melhor aproveitamento dos recursos disponíveis, reforçado quando analisado o ano mais restritivo de cultivo sobre o sistema de menor disponibilidade de N-residual, com a Brisasul mostrando vantagens efetivas no aproveitamento de $\mathrm{N}$ sobre a Barbarasul. 
Tabela 4. Equação de regressão e estimativa da máxima eficiência econômica (MEE) de rendimento de grãos (RG, $\mathrm{kg} \mathrm{ha}^{-1}$ ) pelas doses de $\mathrm{N}$ em aveia

\begin{tabular}{|c|c|c|c|}
\hline \multirow{2}{*}{ Cultivar } & \multirow{2}{*}{ Equação $\left(R G=b_{0} \pm b_{1} x \pm b_{2} x^{2}\right)$} & N/MEE & $\mathrm{RG}_{\mathrm{E}}$ \\
\hline & & \multicolumn{2}{|c|}{$\left(\mathrm{kg} \mathrm{ha}^{-1}\right)$} \\
\hline \multicolumn{4}{|c|}{ Sistema soja/aveia Ano 2011} \\
\hline Barbarasul & $2997+26,5 x-0,20 x^{2}$ & 58 & 3861 \\
\hline Brisasul & $3202+30,4 x-0,20 x^{2}$ & 68 & 4344 \\
\hline \multicolumn{4}{|c|}{ Sistema soja/aveia Ano 2012} \\
\hline Barbarasul & $2668+11 x-0,06 x^{2}$ & 65 & 3129 \\
\hline Brisasul & $2636+15,34 x-0,11 x^{2}$ & 55 & 3146 \\
\hline \multicolumn{4}{|c|}{ Sistema milho/aveia Ano 2011} \\
\hline Barbarasul & $1942+25,16 x-0,13 x^{2}$ & 85 & 3141 \\
\hline Brisasul & $2061+25,71 x-0,17 x^{2}$ & 66 & 3017 \\
\hline \multicolumn{4}{|c|}{ Sistema milho/aveia Ano 2012} \\
\hline Barbarasul & $1178+39,06 x-0,21 x^{2}$ & 85 & 2980 \\
\hline Brisasul & $1560+38,42 x-0,20 x^{2}$ & 88 & 3392 \\
\hline
\end{tabular}

Pavinato et al. (2008) atingiram, em milho, a máxima produtividade de grãos com de $289 \mathrm{~kg} \mathrm{ha}^{-1}$ de $\mathrm{N}$ porém com maior eficiência econômica com $157 \mathrm{~kg} \mathrm{ha}^{-1}$. Portanto, concluíram que a máxima produtividade de grãos pela eficiência técnica não resulta em melhores rendimentos num contexto geral sobre a produção. Fato também observado em cereais como arroz (Freitas et al., 2008) e trigo (Wendling et al., 2007). Em seus estudos, Kolchinski \& Schuch (2003) encontraram maior eficiência de produtividade de grãos pelo $\mathrm{N}$ em aveia branca, ao redor de $70 \mathrm{~kg} \mathrm{ha}^{-1}$ entretanto com genótipos que evidenciavam forte tendência à produção de biomassa total. Ressalta-se que são resultados similares aos obtidos nesta pesquisa porém com genótipos elite de estatura reduzida e com forte direcionamento à elaboração de grãos; contudo, o $\mathrm{N}$ é, sem dúvida, o nutriente que produz maiores resultados sobre a aveia sendo o principal limitante da produção de biomassa e de grãos. Portanto, é notória a necessidade de estudos que viabilizem a eficiência de uso do $\mathrm{N}$ junto ao desenvolvimento de genótipos mais ajustados a tecnologias que promovam em sustentabilidade da agricultura nacional.

\section{Conclusões}

1. Existe tendência de crescimento na taxa de biomassa em aveia com o incremento das doses de $\mathrm{N}$-fertilizante nos sistemas de cultivo, condição nem sempre acompanhada da maior produtividade de grãos.

2. A cultivar Brisasul mostra maior eficiência no aproveitamento do $\mathrm{N}$ à elaboração de biomassa e grãos, independente do sistema de produção. Inclusive, a definição da dose ajustada em aveia permite resultados mais vantajosos pela análise da máxima eficiência econômica de produtividade de grãos.

\section{Agradecimentos}

Ao CNPq, à CAPES, à FAPERGS e à UNIJUI, pelo aporte dos recursos destinados ao desenvolvimento deste estudo e pelas bolsas de Iniciação Científica e Tecnológica, de Apoio Técnico, de Pós-graduação e de Produtividade em Pesquisa.

\section{Literatura Citada}

Araus, J. L.; Slafer, G. A.; Royo, C.; Serret, M. D. Breeding for yield potential and stress adaptation in cereals. Critical Reviews in Plant Science, v.27, p.377-412, 2008. http://dx.doi. org/10.1080/07352680802467736

Barraclough, P. B.; Howarth, J. R.; Jones, J.; Lopez-Bellido, R.; Parmar, S.; Shepherd, C. E.; Hawkesford, M. J. Nitrogen efficiency of wheat: Genotypic and environment variation and prospects for improvement. European Journal of Agronomy, v.33, p.1-11, 2010. http://dx.doi.org/10.1016/j.eja.2010.01.005

Benin, G.; Bornhofen, E.; Beche, E.; Pagliosa, E. S.; Silva, C. L. da; Pinnow, C. Agronomic performance of wheat cultivars in response to nitrogen fertilization levels. Acta Scientiarum Agronomy, v.34, p.275-283, 2012. http://dx.doi.org/10.4025/actasciagron. v34i3.14468

Carvalho, F. I. F. de; Oliveira, A. C. de; Valério, I. P.; Benin, G.; Schmidt, D. A. M.; Hartwig, I.; Ribeiro, G.; Silveira, G. da. Barbarasul: A high-yielding and lodging-resistant white oat cultivar. Crop Breeding and Applied Biotechnology, v.9, p.96-99, 2009. http:// dx.doi.org/10.12702/1984-7033.v09n01a13

Cazetta, D. A.; Fornasieri Filho, D.; Arf, O.; Germani, R. Qualidade industrial de cultivares de trigo e triticale submetidos à adubação nitrogenada no sistema de plantio direto. Bragantia, v.67, p.741750, 2008. http://dx.doi.org/10.1590/S0006-87052008000300024

Costa, L.; Zucareli, C.; Riede, C.R. Parcelamento da adubação nitrogenada no desempenho produtivo de genótipos de trigo. Revista Ciência Agronômica, v.44, p.215-224, 2013. http://dx.doi. org/10.1590/S1806-66902013000200002

Cruz, C. D. Programa Genes: Versão Windows; Aplicativo computacional em genética e estatística. Viçosa: UFV, 2013. 382p.

Dencic, S.; Mladenov, N.; Kobiljski, B. Effects of genotype and environment on breadmaking quality in wheat. International Journal of Plant Production, v.5, p.71-82, 2011.

Espindula, M. C.; Rocha, V. S.; Souza, M. A. de; Grossi, J. A. S.; Souza, L. T. de. Doses e formas de aplicação de nitrogênio no desenvolvimento e produção da cultura do trigo. Ciência e Agrotecnologia, v.34, p.1404-1411, 2010.

Flores, R. A.; Urquiaga, S. S.; Alves, B. J. R.; Collier, L. S.; Morais, R. F. de; Prado, R. de M. Adubação nitrogenada e idade de corte na produção de matéria seca do capim-elefante no Cerrado. Revista Brasileira de Engenharia Agrícola e Ambiental. v.16, p.1282-1288, 2012. http://dx.doi.org/10.1590/S1415-43662012001200004

Foulkes, M. J.; Hawkesford, M. J.; Barraclough, P. B.; Holdsworth, M. J.; Kerr, S.; Kightley, S.; Shewry, P. R. Identifying traits to improve the nitrogen economy of wheat: Recent advances and future prospects. Field Crops Research, v.114, p.329-342, 2009. http:// dx.doi.org/10.1016/j.fcr.2009.09.005

Freitas, T. F. S. de; Silva, P. R. F. da; Mariot, C. H. P.; Menezes, V. G. Anghinoni, I.; Bredemeier, C.; Vieira, V. M. Produtividade de arroz irrigado e eficiência da adubação nitrogenada influenciadas pela época da semeadura. Revista Brasileira de Ciência do Solo, v.32, 2397-2405, 2008. http://dx.doi.org/10.1590/S010006832008000600018

Hawerroth, M. C.; Carvalho, F. I. F.; Oliveira, A. C.; Silva, J. A. G.; Gutkoski, L. C.; Sartori, J. F.; Woyann, L. G.; Barbieri, R. L.; Hawerroth, F. J. Adaptability and stability of white oat cultivars as to chemical composition of the caryopsis. Pesquisa Agropecuária Brasileira, v.48, p.42-50, 2013. http://dx.doi.org/10.1590/S0100204X2013000100006 
Heinemann, A. B.; Stone, L. F.; Didonet, A. D.; Trindade, M. G.; Soares, B. B.; Moreira, J. A. A.; Canovas, A. D. Eficiência de uso da radiação solar na produtividade de trigo decorrente da adubação nitrogenada. Revista Brasileira de Engenharia Agrícola e Ambiental, v.10, p.352-356, 2006. http://dx.doi.org/10.1590/ S1415-43662006000200015

Kolchinski, E. M.; Schuch, L. O. B. Eficiência no uso do nitrogênio por cultivares de aveia branca de acordo com a adubação nitrogenada. Revista Brasileira de Ciência do Solo, v.27, p.1033-1038, 2003. http://dx.doi.org/10.1590/S0100-06832003000600007

Ma, B. L.; Wu, T. Y.; Tremblay, N.; Deen, W.; Mclaughlin, N. B.; Morrison, M. J.; Stewart, G. On-farm assessment of the amount and timing of nitrogen fertilizer on ammonia volatilization. Agronomy Journal, v.102, p.134-144, 2010. http://dx.doi. org/10.2134/agronj2009.0021

Oliveira, A. C. de; Crestani, M.; Carvalho, F. I. F. de; Silva, J. A. G. da; Valério, I. P.; Hartwig, I.; Benin, G.; Schmidt, D. A. M.; Bertan, I. Brisasul: A new high-yielding white oat cultivar with reduced lodging. Crop Breeding and Applied Biotechnology, v.11, p.370374, 2011.

Parry, M. A. J.; Reynolds, M.; Salvucci, M. E.; Raines, C.; Andralojc, J. Raising yield potential of wheat. II. Increasing photosynthetic capacity and efficiency. Journal of Experimental Botany, v.62, p.453-467, 2011. http://dx.doi.org/10.1093/jxb/erq304

Pavinato, P. S.; Ceretta, C. A; Giotto, E.; Moreira, I. C. L. Nitrogênio e potássio em milho irrigado: Análise técnica e econômica da fertilização. Ciência Rural, v.38, p.358-364, 2008. http://dx.doi. org/10.1590/S0103-84782008000200010

Penckowski, L. H.; Zagonel, J.; Fernandes, E. C. Nitrogênio e redutor de crescimento em trigo de alta produtividade. Acta Scientiarum Agronomy, v.31, p.473-479, 2009.

Prando, A. M.; Zucarelli, C.; Fronza, V.; Oliveira, F. A.; Oliveira Júnior, A. Características produtivas do trigo em função de fontes e doses de nitrogênio. Pesquisa Agropecuária Tropical, v.43, p.34-41, 2013. http://dx.doi.org/10.1590/S1983-40632013000100009

Rocha, F. A.; Martinez, M. A.; Matos, A. T.; Cantarutti, R. B.; Silva, J. O. Modelo numérico do transporte de nitrogênio no solo. Parte II: Reações biológicas durante a lixiviação. Revista Brasileira de Engenharia Agrícola e Ambiental, v.12, p.54-61, 2008. http:// dx.doi.org/10.1590/S1415-43662008000100008
Silva, E. C.; Muraoka, T.; Buzetti, S.; Trivelin, P. C. O. Manejo de nitrogênio no milho sob plantio direto com diferentes plantas de cobertura, em latossolo vermelho. Pesquisa Agropecuária Brasileira, v.41, p.477-486, 2006. http://dx.doi.org/10.1590/S0100204X2006000300015

Silva, J. A. G.; Fontaniva, C.; Costa, J. S. P.; Krüger, C. A. M. B.; Ubessi, C.; Pinto, F. B.; Arenhardt, E. G.; Gewehr, E. Uma proposta na densidade de semeadura de um biotipo atual de cultivares de aveia. Revista Brasileira de Agrociência, v.18, p.253-263, 2012.

Simili, F. F.; Reis, R. A.; Furlan, B. N.; Paz, C. C. P.; Lima, M. L. P.; Bellingieris, P. A. Resposta do híbrido de sorgo-sudão à adubação nitrogenada e potássica: Composição química e digestibilidade in vitro da matéria orgânica. Ciência e Agrotecnologia, v.32, p.474-480, 2008. http://dx.doi. org/10.1590/S1413-70542008000200020

Siqueira Neto, M.; Piccolo, M. C.; Venzke Filho, S. P.; Feigl, B. J.; Cerri, C. C. Mineralização e desnitrificação do nitrogênio no solo sob sistema plantio direto. Bragantia, v.69, p.923-936, 2010. http:// dx.doi.org/10.1590/S0006-87052010000400019

Takayama, T.; Ishikawa, N.; Taya, S. The effect to the protein concentration and flour quality of nitrogen fertilization at 10 days after heading in wheat. Japan Agricultural Research Quarterly, v.40, p.291-297, 2006. http://dx.doi.org/10.6090/ jarq. 40.291

Teixeira Filho, M. C. M.; Buzetti, S.; Andreotti, M.; Arf, O.; Benett, C. G. S. Doses, fontes e épocas de aplicação de nitrogênio em trigo irrigado em plantio direto. Pesquisa Agropecuária Brasileira, v.45, p.797-804, 2010. http://dx.doi.org/10.1590/S0100204X2010000800004

Viola, R.; Benin, G.; Cassol, L. C.; Pinnow, C.; Flores, M. F.; Bornhofen, E. Adubação verde e nitrogenada na cultura do trigo em plantio direto. Bragantia, v.72, p.20-28, 2013. http://dx.doi.org/10.1590/ S0006-87052013005000013

Wendling, A.; Eltz, F. L. F.; Cubilla, M. M.; Amado, T. J. C.; Mielniczuk, J.; Lovato, T. Recomendação de adubação nitrogenada para trigo em sucessão ao milho e soja sob sistema de plantio direto no Paraguai. Revista Brasileira de Ciência do Solo, v.31, p.985-994, 2007. http://dx.doi.org/10.1590/S010006832007000500015 